\title{
An Indian Perspective on the Use of Fluticasone/Formoterol in Asthma and Chronic Obstructive Pulmonary Disease Patients
}

\author{
Rahul Sharma, Zafar Ahmad Iqbal' ${ }^{1}$, Hemant Kalra², Abhinav Guliani ${ }^{3}$, Anil K. Singh ${ }^{4}$, Akshay Budhraja ${ }^{5}$, Gaurav Jain ${ }^{6}$, Bharat Mehrotra ${ }^{7}$, Loveleen Mangla ${ }^{8}$, \\ Avi Kumar ${ }^{9}$, Vinay Purohit ${ }^{10}$, Monika Chinda ${ }^{10}$ \\ Department of Pulmonary Medicine, Yatharth Hospital, Noida, ${ }^{4}$ Department of Pulmonary Medicine, Chandan Hospital, Lucknow, ${ }^{7}$ Chest Clinic, Kanpur, Uttar \\ Pradesh, 'Department of Pulmonary Medicine, Fortis Hospital, Mohali, Punjab, ${ }^{2}$ Department of Pulmonology, MGS Hospital, ${ }^{3}$ Department of Chest Diseases, Sir \\ Gangaram Hospital, ${ }^{5}$ Department of Chest, Akash Hospital, ${ }^{6}$ Department of Chest, Max Hospital, ${ }^{9}$ Department of Chest Diseases, Fortis Escorts Heart Institute, Delhi, \\ ${ }^{8}$ Department of Pulmonary Medicine, Metro Hospital, Faridabad, Haryana, ${ }^{10}$ Respiratory Division, Medical Services, Lupin LTD, Mumbai, Maharashtra, India
}

\section{Abstract}

Despite rapidly evolving health-care systems, India continues to have a high disease burden for asthma and chronic obstructive pulmonary disease (COPD). The Asia-Pacific Asthma Insights and Management survey clearly revealed that asthma management remains very poor with worst clinical outcomes in India. Potent inhaled corticosteroids (ICS) and quick onset of long-acting beta2-agonist (LABA) are considered to be optimal dual therapy for management of asthma and COPD. Fluticasone's long-term action against inflammation and formoterol's rapid long-term bronchodilator action are vital clinical attributes for optimal asthma maintenance treatment. In an 8- and 12-week trial, dual therapy of fluticasone and formoterol (FF) reported lung function improvements and better control of asthma than its monotherapy. A large clinical study revealed mild adverse events of dual FF than other dual ICS-LABA combinations. Recent pooled analysis of asthma showed that fluticasone shares a lower risk of pneumonia in asthma. Dual ICS-LABA therapies are preferred in COPD individuals with history of exacerbations. Numerous clinical studies showed significant efficacy, dose adjustments/switching, and safety outcomes with dual FF therapy in asthma and COPD. Dual FF inhaler therapy ensures highly potent anti-inflammatory activity and sustained bronchodilation, thus making this a preferred combination in terms of efficacy, safety, and patient adherence in asthma and COPD. This present review focuses on the combination therapy of formoterol and fluticasone for managing asthma and COPD.

Keywords: Asthma, chronic obstructive pulmonary disease, dual fluticasone and formoterol, dual inhaled corticosteroid-long-acting beta2-agonist, inhaler

\section{INTRODUCTION}

The chronicity of asthma is manifested by recurrent attacks of breathlessness and wheezing. ${ }^{[1]}$ According to the World Health Organization, India has more than 15 million asthmatics, and among them, more than $10 \%$ of asthmatics are children. Nearly more than 2 out of 100 adults are diagnosed with asthma in India. ${ }^{[2]}$ Notably, India has the largest asthma-related mortality rate $(22.3 \%)$ worldwide. However, the exact prevalence and true burden of asthma still remains unknown or underestimated. In the Asia-Pacific Asthma Insights and Management (AP-AIM) largest survey, almost $50 \%$ of asthmatics in India reported that polluted air with dust $(49 \%)$ is the main trigger factor. Likewise, climate variations (27\%), toxic substances (24\%), smoking (23\%), and cold beverages (29\%) were also reported as asthma triggers. ${ }^{[3]}$

\begin{tabular}{|l|l|}
\hline \multicolumn{3}{|c|}{ Access this article online } \\
\hline Quick Response Code: & Website: \\
& www.ijrc.in \\
\hline & \\
& \\
\end{tabular}

The AP-AIM study reported that $91 \%$ of Indian asthmatics claimed that their disease was well controlled. However, based on the Global Initiative for Asthma (GINA) guideline measurements, it was revealed that not a single patient had well-controlled asthma and $40 \%$ of patients had uncontrolled asthma. Furthermore, $63 \%$ and $38 \%$ of patients (who had previously claimed to have adequate asthma control over the

Address for correspondence: Dr. Monika Chinda, Respiratory Division, Medical Services, Lupin LTD, Mumbai, Maharashtra, India.

E-mail: monika.chinda24@gmail.com

This is an open access journal, and articles are distributed under the terms of the Creative Commons Attribution-NonCommercial-ShareAlike 4.0 License, which allows others to remix tweak, and build upon the work non-commercially, as long as appropriate credit is given and the new creations are licensed under the identical terms.

For reprints contact: WKHLRPMedknow_reprints@wolterskluwer.com

How to cite this article: Sharma R, Iqbal ZA, Kalra H, Guliani A, Singh AK, Budhraja A, et al. An Indian perspective on the use of fluticasone/formoterol in asthma and chronic obstructive pulmonary disease patients. Indian $\mathrm{J}$ Respir Care 2021;10:196-200.

Received: $21-12-2020$

Accepted: 02-05-2021

Revised: 26-04-2021 Published: 14-06-2021 
past 1 month) reported to have insufficiently controlled and uncontrolled asthma, respectively. Every year, an average of 8.4 exacerbations were reported by Indian patients with asthma, wherein each episode lasted for approximately 4 days. Majority of Indian patients preferred the oral route of asthma medication. Controller medications were used only by $36 \%$ of asthmatics and rescue inhalers by $50 \%$ of asthmatics. Low usage of inhaled controller medications was considered to be the main cause of concern. According to the Indian panel of doctors, uncontrolled asthma is mainly due to patient noncompliance (90\%) and presence of several phenotypes $(5 \%-10 \%)$. Overall, the outcomes of AP-AIM clearly revealed that asthma management remains very poor with worst clinical outcomes in India. ${ }^{[3]}$

\section{Asthma Management: Focus on India}

Based on current evidence, GINA (2020) has recommended regular use of inhaled corticosteroids (ICSs) at small doses or ICS-formoterol in small doses for mild asthma, to decrease high severity of exacerbations. ${ }^{[4]}$

In uncontrolled asthmatic, the optimal step-up is to administer small doses of ICS/long-acting beta2-agonist (LABA) together. Despite receiving other therapies, small doses of ICS-formoterol can decrease high severity of exacerbations than standard treatment in combination with SABA. ${ }^{[4]}$ Likewise, a five-step treatment approach is recommended by the Joint Indian Chest Society and the National College of Chest Physicians (NCCP) (2015) to achieve effective control of stable asthma. They have recommended small doses of ICS/LABA as optimal controller if symptoms are present between more than twice a month and twice a week along with no nighttime symptoms. In addition, small dose of ICS/LABA as optimal controller is also recommended if symptoms are presently more than two times each week along with nighttime symptoms or in uncontrolled asthma in spite being on minimal doses of ICS. ${ }^{[1]}$

\section{Beneficial Role of Inhaled Corticosteroid/ Long-acting Beta2-agonist Combination in Asthma}

ICS/LABA fixed combination is clinically preferred for initiating therapy in Indian asthmatic patients. Fixed combination inhalers of ICS/LABA are both convenient and feasible than two separate inhalers to improve patient compliance ${ }^{[5,6]}$ Several ICS/LABA fixed combination inhalers such as budesonide/formoterol and fluticasone/salmeterol are widely available and one among them being fluticasone/formoterol. Fluticasone along with formoterol is a well-established ICS-LABA dual therapy which is widely available globally. A pooled five randomized studies revealed that dual therapy of fluticasone and formoterol (FF) markedly elevated forced expiratory volume in $1 \mathrm{~s}$ (FEV1) before and after dose administration from baseline better than monotherapy. The study outcomes demonstrated significant improvement in asthma symptoms, no night awakenings, and less usage of rescue therapies by dual therapy of FF. Moreover, significantly fewer patients experienced exacerbations annually due to dual FF than with its monotherapies. ${ }^{[5]}$ In an 8- and 12-week trial, dual therapy of FF also reported quick response, maintained lung function improvement, and better control of asthma than its monotherapy. ${ }^{[6]}$

\section{Clinical Attributes of Fluticasone/Formoterol in Asthma}

Potent ICS and quick onset of LABA are necessary clinical attributes required in an optimal dual therapy for managing asthma. FF has unique beneficial clinical attributes to effectively manage asthma [Figure 1]. Fluticasone's long-term action against inflammation and formoterol's quick and sustained bronchodilator action are vital clinical attributes for optimal maintenance treatment. Overall, dual ICS/LABA inhaler improves patient compliance to asthma therapy. ${ }^{[7]}$ Notably, the Indian panel of doctors preferred initiating with dual FF for managing asthma in difficult-to-treat patients and uncompliant patients.

\section{Dual therapy of fluticasone/formoterol: Safe switching and step-down in asthma}

A randomized and open-label trial assessed switching effects of high-dose fluticasone and salmeterol (FS) $(1000 / 100 \mu \mathrm{g})$ to FF $(1000 / 40 \mu \mathrm{g})$ and then step-down to manage asthma. Its findings suggested that switching and step-down doses can be easily achieved with good asthma control and without any rise in severity of exacerbations. ${ }^{[8]}$ Another study revealed that changing to or starting fluticasone/formoterol combination leads to low acute respiratory event rates and noninferior clinical outcomes as compared to fluticasone/salmeterol. ${ }^{[9]}$

\section{Long-term clinical experience of fluticasone/formoterol in asthma}

An open-label trial showed that twice-daily therapy of FF $(100 / 10$ or $250 / 10 \mu \mathrm{g})$ had long-term effective asthma control $(0.5$ and 1 year $)$. Significant $(P=0.001)$ and sustained improvements were observed in most of the secondary endpoints. The safety profile (36.9\%) of FF was similar to other 12-month studies conducted for dual FS (250/50 $\mu$ g b.i.d.) and dual budesonide and formoterol. Mild-to-moderate range of adverse events was observed. Pretreatment baseline lung function was significantly improved and maintained over 0.5 - and 1-year therapy duration. ${ }^{[6,10]}$ Another two open-label trials also showed that long-term dual therapy of FF administered for more than 12 months had decreased severe risk exacerbations. ${ }^{[11]}$

\section{Comparative evidences of fluticasone/formoterol in asthma}

An open-label study demonstrated noninferior efficacy of dual FF (100/10 or $250 / 10 \mu \mathrm{g}$ b.i.d.) to dual FS $(100 / 50$ or $250 / 50 \mu \mathrm{g}$ b.i.d.) in asthma. Dual FF therapy showed quicker bronchodilator activity than dual 
Sharma, et al.: Fluticasone/formoterol in asthma and COPD patients

\begin{tabular}{|c|c|}
\hline Fluticasone (ICS) & Formoterol (LABA) \\
\hline $\begin{array}{l}\text { - Potent anti-inflammatory action. } \\
\text { - Rapidly induced protective action. } \\
\text { - Systemic availability via the lungs } \\
\text { versus other ICSs } \\
\text { (beclomethasone, budesonide, } \\
\text { flunisolide) via oral } \\
\text { bioavailability. } \\
\text { - High corticosteroid action than } \\
\text { other ICSs (beclomethasone, } \\
\text { budesonide, flunisolide). }\end{array}$ & $\begin{array}{l}\text { - Rapid onset of action } \\
\text { - Selective } \beta 2 \text {-adrenoceptor } \\
\text { agonist than salmeterol as } \\
\text { partial agonist. } \\
\text { - Sustained action with better } \\
\text { bronchodilation as } \\
\text { compared to salmeterol. } \\
\text { - Quick bronchodilator } \\
\text { action ensures faster } \\
\text { lung diffusion. }\end{array}$ \\
\hline
\end{tabular}

Figure 1: Beneficial clinical attributes of fluticasone/formoterol in asthma. Dual therapy of fluticasone/formoterol: Safe switching and step-down in asthma

FS throughout 12 weeks $(P<0.001)$. Four-fold high bronchodilator activity within 5 min was achieved with dual $\mathrm{FF}$ as compared to dual FS [Figure 2]. ${ }^{[6]}$ Similar efficacy was demonstrated with dual FF therapy for pulmonary function tests, less usage of rescue therapies, symptomatic and nocturnal awakening/health status scores, and severity of exacerbations. Further, dual FF showed similar safety outcomes to dual FS. ${ }^{[10]}$ The Indian panel of doctors preferred dual FF over dual FS in asthma patients with more morning and evening symptoms. They even preferred switching their patients from dual FS to dual FF due to rapid control offered by the latter.

A 12 -week study showed that dual FF $(250 / 12 \mu \mathrm{g}$ b.i.d.) had significant superiority to dual budesonide and formoterol (400/12 $\mu \mathrm{g}$ b.i.d.) with respect to pulmonary function $(P=0.01)$ and control of asthma $(P=0.02)$ in uncontrolled or partial controlled asthma. Similar safety outcomes were also observed. ${ }^{[12]}$ Another study showed that dual FF (250/10 $\mu$ g b.i.d.) and dual budesonide and formoterol (400/12 $\mu \mathrm{g}$ b.i.d.) provided similar mean FEV1 changes at 1 month in moderate-to-severe asthma. ${ }^{[6]}$ Similar efficacy was observed for asthma control, symptomatic-free, and nocturnal awakening-free scores with both the treatments. Similar safety outcomes were also observed. ${ }^{[10]}$

\section{Symptom improvement in Indian patients with persistent asthma}

A first real-world Indian study determined the effectiveness and safety of fluticasone propionate/formoterol fumarate $(100 / 6 \mathrm{mcg}$ or $250 / 6 \mathrm{mcg})$ in persistent asthmatic patients for 24 weeks. At the end of the study, a ten-fold increase was reported in patients achieving asthma control from $8.4 \%$ at baseline to $80.7 \%$. Significant peak expiratory flow rate improvement (evening and morning) was observed at week 24 from baseline. Fluticasone/formoterol was safe and well tolerated in Indian asthmatic patients. The study concluded that a fixed combination of fluticasone/formoterol safely achieved symptomatic control for the long-term management of asthma in Indian patients. ${ }^{[13]}$

\section{Safety of fluticasone/formoterol in asthma}

The largest real-world study revealed mild adverse events with

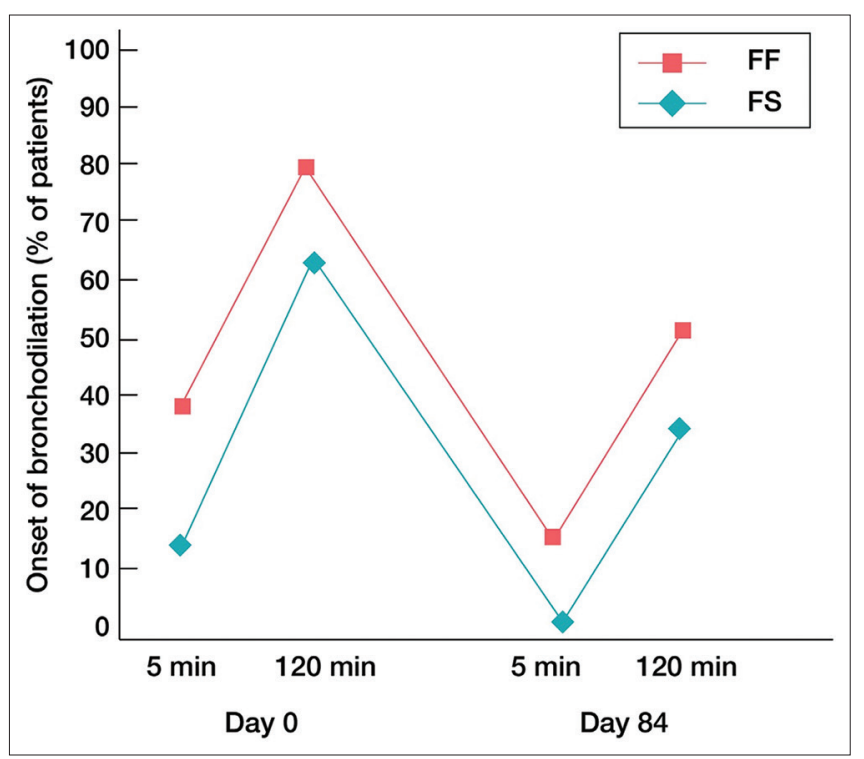

Figure 2: Rapid response of dual fluticasone and formoterol in asthma

dual FF than other dual ICS-LABA combinations. ${ }^{[7]}$ Recent data have stated an increased risk of pneumonia related to fluticasone treatment. However, $<1$ pneumonia episode was detected with dual FF therapy in a recent pooled analysis. Long-term data of dual FF (100/10 or 250/10 mg twice daily) conducted in 752 asthmatics showed that not more than 8 patients had pneumonia. Likewise, a meta-analysis of controlled studies showed 19 and 10 pneumonia episodes/1000 patient-years with placebo and budesonide, respectively. Notably, a secondary study demonstrated an equivalent risk of pneumonia both with fluticasone and budesonide. Thus, recent pooled analysis of asthma treatment highlighted a viewpoint that fluticasone shares no increased risk of pneumonia in asthma. ${ }^{[5]}$ Adverse events such as dysphonia and oral thrush were more commonly observed with dual budesonide and formoterol, whereas dual FF was found to be relatively more tolerable with a better safer profile. Notably, at higher doses, dual FF was well tolerated and even its taste is better than dual budesonide and formoterol as reported by the Indian panel of doctors.

\section{Overview: Chronic Obstructive Pulmonary DISEASE IN INDIA}

Globally, chronic obstructive pulmonary disease (COPD) ranks third in line due to high mortality rates. ${ }^{[14]}$ Currently, around 30 million Indians with COPD. However, the exact COPD burden is unknown. ${ }^{[15]}$ India has the highest mortality rate in the world with significant and growing COPD mortality rate. ${ }^{[16]}$ Management of COPD is challenging due to its heterogeneous nature and unknown pathophysiology of the disease. ${ }^{[17]}$

Prescription patterns in chronic obstructive pulmonary disease patients: An Indian perspective

A recent Indian prospective study (2019) analyzed that 
ICS-LABA was the preferred combinational therapy over monotherapy in drugs prescribing pattern for COPD. ${ }^{[18]}$ Another recent Indian study (2020) concluded that prescribing pattern was in concordance with the current GOLD guidelines in the management of patients with COPD. ${ }^{[19]}$

\section{Chronic obstructive pulmonary disease management: Focus on India}

Several studies have confirmed that dual ICS and LABA therapy lowers the severity of exacerbations and improves lung function and health status in COPD better than its monotherapies. Dual ICS-LABA therapies are preferred in COPD individuals with history of exacerbations. ICSs may prove to be beneficial in eosinophilic lung inflammation or in individuals with history of asthma or COPD-asthma overlap. ${ }^{[17]}$ The GOLD guidelines have strongly recommended ICS-LABA for management of stable COPD. ${ }^{[14]}$ The ICS/ NCCP consensus (2014) have recommended the use of ICS-LABA against the LABA monotherapy in COPD individuals with $<50 \% \mathrm{FEV} 1$ or in recurrent exacerbations. ${ }^{[15]}$

\section{Beneficial Role of Inhaled Corticosteroid/ Long-Acting beta2-agonist Combination in Chronic Obstructive Pulmonary Disease}

A largest study named Towards a Revolution in COPD Health was conducted in more than 6110 patients for 3 years. The study outcomes showed that dual ICS-LABA therapy reduced exacerbations and improved pulmonary function and quality of life than LABA monotherapy. In addition, dual ICS-LABA therapy reduced cardiac-related events. A Cochrane analysis conducted in more than 11,790 patients showed reduced exacerbations and improved symptomatic scores, pulmonary function, and quality of life with dual ICS-LABA than LABA monotherapy. ${ }^{[15]}$
The Efficacy of Fluticasone Propionate/Formoterol in Chronic Obstructive Pulmonary Disease Treatment trial in chronic obstructive pulmonary disease

The Efficacy of Fluticasone Propionate/Formoterol in COPD Treatment trial was a randomized controlled trial which compared dual FF (500/20 or 250/10 $\mu$ g twice daily) with formoterol $(12 \mu \mathrm{g}$ bid) for 52 weeks in COPD. Fewer discontinuations were reported with fluticasone/formoterol $500 / 20 \mu \mathrm{g}(21 \%)$ and $250 / 10 \mu \mathrm{g}(23.5 \%)$ as compared to formoterol (26\%). Greater pre- and postdose FEV1 was reported with dual FF $(500 / 20 \mu \mathrm{g})$ than with formoterol $(P \leq 0.039)$. High responder rates related to St. George's Respiratory Questionnaire for COPD were observed with dual FF as compared to formoterol alone $(P \leq 0.054)$. Lower symptomatic score and breathlessness score were reported with dual FF versus formoterol alone $(P \leq 0.066)$. Post hoc analysis showed a significant prolonged time for the first clinically important deterioration episode with dual FF (500/20 $\mu \mathrm{g}$ and 250/10 $\mu \mathrm{g})$ than with formoterol alone [Figure 3]. ${ }^{[20]}$

\section{Efficacy of fluticasone and formoterol in Indian patients} with chronic obstructive pulmonary disease

An Indian prospective and observational study highlighted the favorable therapeutic performance of combined inhaled bronchodilators and corticosteroids (FF) in severe COPD patients. The results demonstrated an increase in FEV1, 28 symptom-free days/patient during the 6-month period. The study concluded that combined ICSs and long-acting bronchodilators had the potential to improve clinical outcomes and patients' quality of life. ${ }^{[21]}$

\section{Summary of Clinical Studies}

Table 1 lists the summary of various clinical studies.

\begin{tabular}{|c|c|c|c|c|}
\hline Study/year & Country & Design & $\begin{array}{l}\text { Number of } \\
\text { subjects }\end{array}$ & $\begin{array}{c}\text { Study } \\
\text { duration }\end{array}$ \\
\hline \multicolumn{5}{|l|}{ Asthma } \\
\hline Salvi et al./2015 & India & Face-to-face interviews & 400 & 5 months \\
\hline Papi et al./2014 & European countries & Pooled from five randomized studies & 1055 & 8 or 12 weeks \\
\hline $\begin{array}{l}\text { Usmani } \\
\text { et al./2017 }\end{array}$ & European countries & $\begin{array}{l}\text { Randomized controlled, pragmatic, open-label trial } \\
\text { real-life patients }\end{array}$ & 225 & 12 months \\
\hline Ming et al./2017 & European countries & Historical, matched cohort database study & 2472 & - \\
\hline Papi et al./2016 & - & Two open-label trials versus three Cochrane meta-analyses & 752 & 26-60 weeks \\
\hline Cukier et al./2013 & Brazil & $\begin{array}{l}\text { Actively controlled, open-labeled, parallel-group, } \\
\text { multicenter, Phase III study }\end{array}$ & 196 & 12 weeks \\
\hline $\begin{array}{l}\text { Ghoshal } \\
\text { et al./2019 }\end{array}$ & India & $\begin{array}{l}\text { Prospective, open-label, noncomparative, observational, } \\
24 \text {-week multicenter study }\end{array}$ & 385 & 24 weeks \\
\hline \multicolumn{5}{|l|}{ COPD } \\
\hline Kumar et al./2019 & India & Prospective study & 163 & 6 months \\
\hline Srikala et al./2020 & India & Prospective observational study & 301 & 6 months \\
\hline Papi et al./2017 & European countries & Randomized controlled trial & 1765 & 52 weeks \\
\hline Altaf et al./2015 & India & Prospective observational study & 90 & 6 months \\
\hline
\end{tabular}

COPD: Chronic obstructive pulmonary disease 
Sharma, et al.: Fluticasone/formoterol in asthma and COPD patients

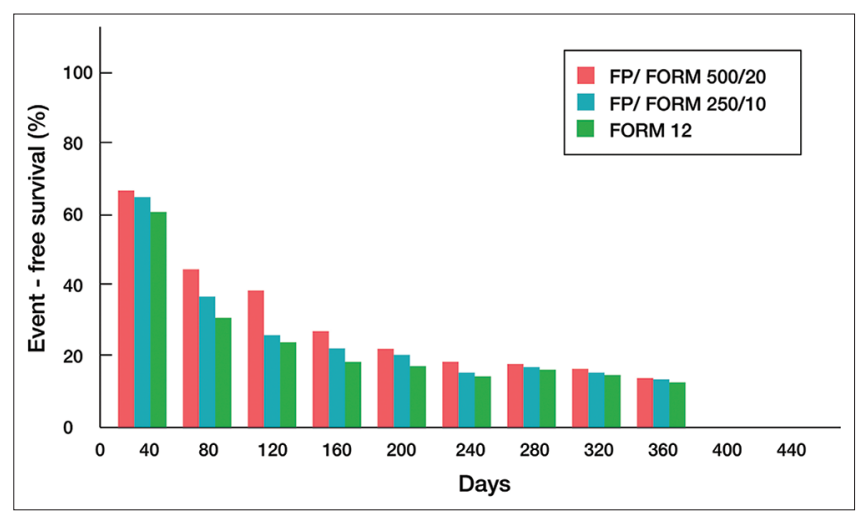

Figure 3: Event occurrence with fluticasone/formoterol in patients with chronic obstructive pulmonary disease. FP/FORM: Fluticasone propionate/ formoterol

\section{ConcLusion}

Despite rapidly evolving health-care systems, India contributes to a high disease burden for asthma and COPD. Numerous clinical studies show the significant efficacy and safety outcomes with dual FF therapy in asthma and COPD. Dual FF inhaled medication ensures high potency action against anti-inflammation and rapid bronchodilation, thus making this a preferred combination with respect to efficacy, safety, and patient adherence in asthma and COPD.

\section{Acknowledgments}

The authors would like to acknowledge Insignia Communications for help in medical writing and editorial work. This work was arranged and funded by Lupin Limited (Mumbai, India).

\section{Financial support and sponsorship}

Nil.

\section{Conflicts of interest}

This paper forms part of a supplement commissioned and funded by Lupin Limited. The supplement contains papers based on presentations from a focused group discussion of health-care professionals held on August 13, 2020, which was also arranged and sponsored by Lupin Limited. All participants received an honorarium from Lupin Limited for their attendance and participation in the advisory meeting. Vinay Purohit and Monika Chinda are employees of Lupin Limited. Other authors have no declarations of interest.

\section{REFERENCES}

1. Agarwal R, Dhooria S, Aggarwal AN, Maturu VN, Sehgal IS, Muthu V, et al. Guidelines for diagnosis and management of bronchial asthma: Joint ICS/NCCP (I) recommendations. Lung India 2015;32:S3-42.

2. Jain N, Satish K, Abhyankar N, Velayudhan N, Gurunathan J. Repeated exacerbation of asthma: An intrinsic phenotype of uncontrolled asthma. Lung India 2019;36:131-8.

3. Salvi SS, Apte KK, Dhar R, Shetty P, Faruqi RA, Thompson PJ, et al.
Asthma Insights and Management in India: Lessons Learnt from the Asia Pacific-Asthma Insights and Management (AP-AIM) Study. J Assoc Physicians India 2015;63:36-43.

4. GINA Main Report-Global Initiative for Asthma. Available from: https://ginasthma.org/gina-reports/. [Last accessed on 2020 Oct 16].

5. Papi A, Price D, Sastre J, Kaiser K, Lomax M, McIver T, et al. Efficacy of fluticasone propionate/formoterol fumarate in the treatment of asthma: A pooled analysis. Respir Med 2015;109:208-17.

6. McKeage K. Fluticasone propionate/formoterol fumarate: A review of its use in persistent asthma. Drugs 2013;73:195-206.

7. Rajesh V,Augustine J, Divya R, Cleetus M. Inhaled formoterol-fluticasone single inhaler therapy in asthma: Real-world efficacy, budget impact, and potential to improve adherence. Can Respir J 2020;2020:8631316.

8. Usmani OS, Kemppinen A, Gardener E, Thomas V, Konduru PR, Callan C, et al. A randomized pragmatic trial of changing to and stepping down fluticasone/formoterol in asthma. J Allergy Clin Immunol Pract 2017;5:1378-87.e5.

9. Wan Yau Ming S, Haughney J, Small I, Wolfe S, Hamill J, Gruffydd-Jones $\mathrm{K}$, et al. Initiating or changing to a fixed-dose combination of Fluticasone propionate/Formoterol over Fluticasone propionate/Salmeterol: A real-life effectiveness and cost impact evaluation. Respir Med 2017;129:199-206.

10. Dissanayake S, Grothe B, Kaiser K. Fluticasone/formoterol: A new single-aerosol combination therapy for patients with asthma. Respir Med 2012;106 Suppl 1:S20-8.

11. Papi A, Mansur AH, Pertseva T, Kaiser K, McIver T, Grothe B, et al. Long-term fluticasone propionate/formoterol fumarate combination therapy is associated with a low incidence of severe asthma exacerbations. J Aerosol Med Pulm Drug Deliv 2016;29:346-61.

12. Cukier A, Jacob CM, Rosario Filho NA, Fiterman J, Vianna EO, Hetzel JL, et al. Fluticasone/formoterol dry powder versus budesonide/ formoterol in adults and adolescents with uncontrolled or partly controlled asthma. Respir Med 2013;107:1330-8.

13. Ghoshal A, Waghray P, Dsouza G, Saluja M, Agarwal M, Goyal A, et al. Real-world evaluation of the clinical safety and efficacy of fluticasone/ formoterol FDC via the Revolizer ${ }^{\mathbb{R}}$ in patients with persistent asthma in India. Pulm Pharmacol Ther 2020;60:101869.

14. GOLD Guidelines for COPD. Available from: https:/goldcopd.org/ wp-content/uploads/2019/11/GOLD-2020-REPORT-ver1.0wms.pdf. [Last accessed on 2020 Oct 16].

15. Gupta D, Agarwal R, Aggarwal AN, Maturu VN, Dhooria S, Prasad KT, et al. Guidelines for diagnosis and management of chronic obstructive pulmonary disease: Joint recommendations of Indian Chest Society and National College of Chest Physicians (India). Indian J Chest Dis Allied Sci 2014;56 Spec No:5-54.

16. Koul PA. Chronic obstructive pulmonary disease: Indian guidelines and the road ahead. Lung India 2013;30:175-7.

17. Tashkin DP, Strange C. Inhaled corticosteroids for chronic obstructive pulmonary disease: What is their role in therapy? Int J Chron Obstruct Pulmon Dis 2018;13:2587-601.

18. Kumar S, Madhuri G, Wilson A, George T. Study of prescribing pattern of drugs in chronic obstructive pulmonary disease in tertiary care teaching hospital. Indian J Pharm Pract 2019;12:161-6.

19. Srikala TS. V Saika, Babu KR, Eswaraiah MC. Assessment of prescription pattern among COPD patients in departments of General Medicine Ward and Pulmonology in Tertiary Care Hospitals of Khammam Region. Int J Res Pharm Sci 2020;11:1798-806.

20. Papi A, Dokic D, Tzimas W, Mészáros I, Olech-Cudzik A, Koroknai Z, et al. Fluticasone propionate/formoterol for COPD management: A randomized controlled trial. Int $\mathrm{J}$ Chron Obstruct Pulmon Dis 2017;12:1961-71.

21. Altaf M, Zubedi AM, Nazneen F, Kareemulla S, Ali SA, Aleemuddin NM, et al. Cost-effectiveness analysis of three different combinations of inhalers for severe and very severe chronic obstructive pulmonary disease patients at a tertiary care teaching hospital of South India. Perspect Clin Res 2015;6:150-8. 